\title{
An Approach to Evaluating Enterprise Financial Performance Based on the Control Inheritance of Family Businesses with Intuitionistic Fuzzy Information
}

\author{
Hui Liu \\ Zhejiang Gongshang University, Jiaxing, Zhejiang 314003, China \\ Correspondence should be addressed to Hui Liu; liuhui-cjp@163.com
}

Received 28 June 2014; Accepted 9 July 2014; Published 17 July 2014

Academic Editor: Xiaofei Zhao

Copyright (C) 2014 Hui Liu. This is an open access article distributed under the Creative Commons Attribution License, which permits unrestricted use, distribution, and reproduction in any medium, provided the original work is properly cited.

\begin{abstract}
We investigate the multiple attribute decision making problems for evaluating the enterprise financial performance based on the control inheritance of family businesses with intuitionistic fuzzy information. We utilize the intuitionistic fuzzy Bonferroni mean (IFBM) operator to aggregate the intuitionistic fuzzy information corresponding to each alternative and get the overall value of enterprise financial performance and then rank the enterprises and select the most desirable one(s) by using the overall value of enterprise financial performance. Finally, an illustrative example for evaluating the enterprise financial performance based on the control inheritance of family businesses is given to verify the developed approach and to demonstrate its practicality and effectiveness.
\end{abstract}

\section{Introduction}

After the reform and opening up for over 30 years, our country's economic construction has made remarkable achievement, the comprehensive national strength and economic strength have increased apparently, all kinds of economic subjects have different degrees of development in China, and family enterprises as the economic organizations that started late also have undergone earth-shaking changes. The appearance of family enterprises can not only increase employment for our country, expand import and export, and push forward economic development but also they play an important role in academic economics, management theory in providing research object $[1,2]$. Nowadays, China's family enterprises have developed a lot; with the first generation becoming old, there is an emerging split in the succession of the right of control, some family enterprises are on the path towards socialization by introducing professional managers, and some ones with the psychology of "not letting the opportunities go outside Tian" pass the control power to their own family members. While most of the founders of the family enterprises want to pass the power to the next generation by nature, the biggest problems in the sustainable management of family enterprises are the inheritance crisis of enterprises' control power [3-5]. Therefore, in the matter of choosing the professional managers or family heirs, many founders approach carefully [6]. In recent years, more attention is given to inheritance of the control power of China's family business, but the number of specific theory researches is not so much. Although the related researches in foreign countries have longer time history and bigger quantity than those at home, but as our family businesses are very different from foreign ones in the development environment, development phase, cultural traditions background, and so forth, the reference meaning of the foreign research results to our family enterprises is not so big $[7,8]$. Therefore, the academic results that not only make theoretical analysis according to the business theories but also follow the local family businesses' actual development keeping pace with the times to research the control power are few $[9,10]$.

In this paper, we investigate the problems for evaluating the enterprise financial performance based on the control inheritance of family businesses with intuitionistic fuzzy information. The remainder of this paper is set out as follows. In the next section, we introduce some basic concepts related to intuitionistic fuzzy sets and intuitionistic fuzzy 
Bonferroni mean (IFBM) operator. In Section 3, we introduce the problem for evaluating the enterprise financial performance based on the control inheritance of family businesses with intuitionistic fuzzy information. Then, we utilize the intuitionistic fuzzy Bonferroni mean (IFBM) operator to aggregate the intuitionistic fuzzy information corresponding to each alternative. In Section 4, an illustrative example is pointed out. In Section 5, we conclude the paper and give some remarks.

\section{Preliminaries}

In the following, we introduce some basic concepts related to IFS.

Definition 1 (see [11]). An IFS $A$ in $X$ is given by

$$
A=\left\{\left\langle x, \mu_{A}(x), v_{A}(x)\right\rangle \mid x \in X\right\}
$$

where $\mu_{A}: X \rightarrow[0,1]$ and $\nu_{A}: X \rightarrow[0,1]$, with the condition $0 \leq \mu_{A}(x)+\nu_{A}(x) \leq 1, \forall x \in X$. The numbers $\mu_{A}(x)$ and $\nu_{A}(x)$ represent, respectively, the membership degree and nonmembership degree of the element $x$ to the set $A$.

Bonferroni [12] originally introduced a mean type aggregation operator, called Bonferroni mean, which can provide for aggregation lying between the max, min operators, and the logical "or" and "and" operators, which was defined as follows.

Definition 2 (see [12]). Let $p, q \geq 0$, and $a_{i}(i=1,2, \ldots, n)$ be a collection of nonnegative real numbers. Then the aggregation function

$$
\mathrm{BM}^{p, q}\left(a_{1}, a_{2}, \ldots, a_{n}\right)=\left(\frac{1}{n(n-1)} \sum_{\substack{i, j=1 \\ i \neq j}}^{n} a_{i}^{p} a_{j}^{q}\right)^{1 /(p+q)}
$$

is called the Bonferroni mean (BM) operator.

Definition 3 (see [13]). Let $\tilde{a}_{j}=\left(\mu_{j}, v_{j}\right)(j=1,2, \ldots, n)$ be a collection of intuitionistic fuzzy values, and let $p, q>0$. If

$$
\operatorname{IFBM}^{p, q}\left(\tilde{a}_{1}, \tilde{a}_{2}, \ldots, \tilde{a}_{n}\right)=\left(\frac{1}{n(n-1)} \sum_{\substack{i, j=1 \\ i \neq j}}^{n} \tilde{a}_{i}^{p} \widetilde{a}_{j}^{q}\right)^{1 /(p+q)}
$$

then $\operatorname{IFBM}^{p, q}$ is called the intuitionistic fuzzy Bonferroni mean (IFBM) operator.

Based on the operations of the intuitionistic fuzzy values described, we can drive Theorem 4.
Theorem 4. Let $\tilde{a}_{j}=\left(\mu_{j}, v_{j}\right)(j=1,2, \ldots, n)$ be a collection of intuitionistic fuzzy values; then their aggregated value by using the IFBM operator is also a IFFE, and

$$
\begin{aligned}
& \operatorname{IFBM}^{p, q}\left(\tilde{a}_{1}, \tilde{a}_{2}, \ldots, \tilde{a}_{n}\right) \\
& =\left(\frac{1}{n(n-1)} \sum_{\substack{i, j=1 \\
i \neq j}}^{n} \widetilde{a}_{i}^{p} \widetilde{a}_{j}^{q}\right)^{1 /(p+q)} \\
& =\left(\left(1-\prod_{\substack{i, j=1 \\
i \neq j}}^{n}\left(1-\left(\mu_{i}\right)^{p}\left(\mu_{j}\right)^{q}\right)^{1 /(n(n-1))}\right)^{1 /(p+q)},\right. \\
& 1-\left(1-\prod_{\substack{i, j=1 \\
i \neq j}}^{n}\left(1-\left(1-v_{i}\right)^{p}\right.\right. \\
& \left.\left.\left.\times\left(1-v_{j}\right)^{q}\right)^{1 /(n(n-1))}\right)^{1 /(p+q)}\right) .
\end{aligned}
$$

Then IFBM $M^{p, q}$ is called the intuitionistic fuzzy Bonferroni mean (IFBM) operator [13].

\section{An Approach to Evaluating Enterprise Financial Performance Based on the Control Inheritance of Family Businesses with Intuitionistic Fuzzy Information}

With the development of market economy, mergers and acquisitions have become a trend in the development of company. How to effectively analyze and evaluate the financial performance of the listed companies which implemented mergers and acquisitions, how to find the factors which influence the financial performance, and how to adopt effective measures to improve the performance of the companies have become important things. In this section, we consider multiple attribute decision making problems to evaluate the enterprise financial performance based on the control inheritance of family businesses with intuitionistic fuzzy information. Let $A=\left\{A_{1}, A_{2}, \ldots, A_{m}\right\}$ be a discrete set of alternatives, and let $G=\left\{G_{1}, G_{2}, \ldots, G_{n}\right\}$ be the set of attributes. Suppose that $\widetilde{R}=\left(\widetilde{r}_{i j}\right)_{m \times n}=\left(\mu_{i j}, v_{i j}\right)_{m \times n}$ is the intuitionistic fuzzy decision matrix, where $\mu_{i j}$ indicates the degree that the alternative $A_{i}$ satisfies the attribute $G_{j}$ given by the decision maker and $v_{i j}$ indicates the degree that the alternative $A_{i}$ does not satisfy the attribute $G_{j}$ given by the decision maker; $\mu_{i j} \subset[0,1]$, $v_{i j} \subset[0,1], \mu_{i j}+v_{i j} \leq 1, i=1,2, \ldots, m, j=1,2, \ldots, n$.

In the following, we apply the IFBM operator to MADM forevaluating the enterprise financial performance based on the control inheritance of family businesses with intuitionistic fuzzy information. 
Step 1. Utilize the decision information given in matrix $\widetilde{R}$, and the IFBM operator (in general, we can take $p=q=1$ )

$$
\begin{aligned}
& \tilde{r}_{i}=\left(\mu_{i}, v_{i}\right) \\
& =\operatorname{IFBM}^{p, q}\left(\widetilde{r}_{i 1}, \widetilde{r}_{i 2}, \ldots, \widetilde{r}_{i n}\right) \\
& =\left(\frac{1}{n(n-1)} \sum_{\substack{i, j=1 \\
i \neq j}}^{n} \widetilde{r}_{k i}^{p} \widetilde{r}_{k j}^{q}\right)^{1 /(p+q)} \\
& =\left(\left(1-\prod_{\substack{i, j=1 \\
i \neq j}}^{n}\left(1-\left(\mu_{k i}\right)^{p}\left(\mu_{k j}\right)^{q}\right)^{1 /(n(n-1))}\right)^{1 /(p+q)},\right. \\
& 1-\left(1-\prod_{\substack{i, j=1 \\
i \neq j}}^{n}\left(1-\left(1-v_{k i}\right)^{p}\right.\right. \\
& \left.\left.\left.\times\left(1-v_{k j}\right)^{q}\right)^{1 /(n(n-1))}\right)^{1 /(p+q)}\right), \\
& k=1,2, \ldots, m
\end{aligned}
$$

to derive the overall values $\widetilde{r}_{i}(i=1,2, \ldots, m)$ of the alternative $A_{i}$.

Step 2. Calculate the scores $S\left(\widetilde{r}_{i}\right)(i=1,2, \ldots, m)$ of the collective overall intuitionistic fuzzy preference values $\widetilde{r}_{i}(i=$ $1,2, \ldots, m)$ to rank all the alternatives $A_{i}(i=1,2, \ldots, m)$ and then to select the best one(s).

Step 3. Rank all the alternatives $A_{i}(i=1,2, \ldots, m)$ and select the best one(s) in accordance with $S\left(\widetilde{r}_{i}\right)$ and $H\left(\widetilde{r}_{i}\right)(i=$ $1,2, \ldots, m)$.

\section{Numerical Example}

Listed companies play important role in China's market economy. Performance of listed companies affects resources allocation of capital market and has become a common concern of shareholders, creditors, employees, government authorities, and other stakeholders. It is been developed into an important research issue in the field of financial of how to evaluate listed companies' performance reasonably and correctly. Currently, a variety of methods has been developed for enterprise performance evaluation. Many domestic scholars keep working in this field, aiming at building and importing different performance evaluation system. They study the shortage of existing methods, mostly basing on subjective analysis and considerably affected by the academic level of researchers. An integrated system that could combine different performance evaluation methods has not been developed. The existing papers presented a research idea to combine different performance evaluation methods. Using empirical research methods, evaluation results of different financial performance evaluation methods can be calculated. Variation of the results will be analyzed and broken down into some basic impact factors by looking into the process of the method and operating information public by the companies. Factors will be classified in order to find out whether differences of calculation results are reasonable and when a certain method should be applied. In this section, we present an empirical case study of evaluating enterprise financial performances based on the control inheritance of family businesses. The project's aim is to evaluate the best enterprise from the different companies of enterprise financial performances, which provide alternatives of enterprise. The enterprise financial performance of five possible enterprises $A_{i}(i=1,2,3,4,5)$ is evaluated. Assume that an enterprise newly identified an investment with enterprise financial performances, and in order to maximize the expected profit, we need to determine the enterprise financial performances of the five enterprises so as to choose the optimal one. The investment company must take a decision according to the following five attributes: G1 is the debt paying ability; G2 is the operation capability; G3 is the earning capacity; G4 is the development capability. The five possible enterprises $A_{i}(i=1,2,3,4)$ are to be evaluated by using the intuitionistic fuzzy numbers by the decision makers under the above four attributes, and construct the decision matrix as listed in the following matrix $\widetilde{R}=\left(\widetilde{r}_{i j}\right)_{5 \times 4}$ :

$$
\widetilde{R}=\left[\begin{array}{llll}
(0.2,0.5) & (0.2,0.7) & (0.2,0.6) & (0.1,0.6) \\
(0.3,0.7) & (0.6,0.3) & (0.5,0.3) & (0.3,0.4) \\
(0.1,0.6) & (0.4,0.4) & (0.3,0.4) & (0.5,0.2) \\
(0.3,0.8) & (0.2,0.5) & (0.4,0.5) & (0.1,0.5) \\
(0.5,0.1) & (0.3,0.2) & (0.6,0.2) & (0.4,0.2)
\end{array}\right]
$$

Then, we utilize the approach developed to get the most desirable enterprises.

Step 1. Utilize the decision information given in matrix $\widetilde{R}$ and the IFBM operator (in general, we can take $p=q=1$ ) to derive the overall values $\widetilde{r}_{i}(i=1,2, \ldots, m)$ of the enterprises $A_{i}$ :

$$
\begin{array}{ll}
\tilde{r}_{1}=(0.67,0.42), & \widetilde{r}_{2}=(0.59,0.21), \quad \tilde{r}_{3}=(0.70,0.23), \\
\tilde{r}_{4}=(0.48,0.21), & \tilde{r}_{5}=(0.72,0.49) .
\end{array}
$$

Step 2. Calculate the scores $S\left(\widetilde{r}_{i}\right)(i=1,2,3,4,5)$ of the overall intuitionistic fuzzy values $\widetilde{r}_{i}(i=1,2,3,4,5)$ :

$$
\begin{array}{ll}
S\left(\tilde{r}_{1}\right)=0.25, \quad S\left(\tilde{r}_{2}\right)=0.38, \quad S\left(\widetilde{r}_{3}\right)=0.47 \\
S\left(\tilde{r}_{4}\right)=0.27, \quad S\left(\tilde{r}_{5}\right)=0.23 .
\end{array}
$$

Step 3. Rank all the enterprises $A_{i}(i=1,2,3,4,5)$ in accordance with the scores $S\left(\widetilde{r}_{i}\right)(i=1,2,3,4,5)$ of the intuitionistic fuzzy values $\widetilde{r}_{i}(i=1,2,3,4,5): A_{3}>A_{2}>A_{4}>A_{1}>$ $A_{5}$, and thus the most desirable enterprises are $A_{3}$. 


\section{Conclusion}

In the market economy, mergers and acquisitions have become an effective mechanism of Capital Allocation. In recent years, mergers and acquisitions reflect profound changes in corporate governance. With the development of market economy, mergers and acquisitions have become a trend in the development of company. How to effectively analyze and evaluate the financial performance of the listed companies which implemented mergers and acquisitions, how to find the factors which influence the financial performance, and how to adopt effective measures to improve the performance of the companies have become important things. In this paper, we investigate the multiple attribute decision making problems for evaluating the enterprise financial performance based on the control inheritance of family businesses with intuitionistic fuzzy information. We utilize the intuitionistic fuzzy Bonferroni mean (IFBM) operator to aggregate the intuitionistic fuzzy information corresponding to each alternative and get the overall value of enterprise financial performance and then rank the enterprises and select the most desirable one(s) by using the overall value of enterprise financial performance. Finally, an illustrative example for evaluating the enterprise financial performance based on the control inheritance of family businesses is given to verify the developed approach and to demonstrate its practicality and effectiveness.

\section{Conflict of Interests}

The author declares that there is no conflict of interests regarding the publication of this paper.

\section{References}

[1] H. Lv, "Application of fuzzy evaluating model to the assessment of marine service industry in triangular fuzzy setting," Advances in Information Sciences and Service Sciences, vol. 3, no. 9, pp. 162-167, 2011.

[2] Q. Yuan, "Assessment of information security risk with interval intuitionistic trapezoidal fuzzy information," Advances in Information Sciences and Service Sciences, vol. 3, no. 9, pp. 215-220, 2011.

[3] D. Liu, "E-commerce system security assessment based on grey relational analysis comprehensive evaluation," International Journal of Digital Content Technology and Its Applications, vol. 5, no. 10, pp. 279-284, 2011.

[4] Y. Jiang and D. Jiang, "The security assessment method of wireless sensor network with interval grey linguistic variables," International Journal of Digital Content Technology and its Applications, vol. 5, no. 10, pp. 389-395, 2011.

[5] P. Liu and F. Jin, "The multi-attribute group decision making method based on the interval grey linguistic variables," African Journal of Business Management, vol. 4, no. 17, pp. 3708-3715, 2010.

[6] M. Wang and P. Liu, "An extended VIKOR method for investment risk assessment of real estate based on the uncertain linguistic variables," Advances in Information Sciences and Service Sciences, vol. 3, no. 7, pp. 35-46, 2011.
[7] M. Wang and P. Liu, "An extended VIKOR method for investment risk assessment of real estate based on the uncertain linguistic variables," Advances in Information Sciences and Service Sciences, vol. 3, no. 7, pp. 35-43, 2011.

[8] X. Wang, "Model for tourism management with 2-tuple linguistic information," Advances in Information Sciences and Service Sciences, vol. 3, no. 4, pp. 34-39, 2011.

[9] C. Jiang and X. Luo, "An approach to evaluating the exchange rate risk in the international trade with linguistic information," International Journal of Digital Content Technology and Its Applications, vol. 6, no. 17, pp. 365-371, 2012.

[10] L. Xie, "Research on the developmental level evaluation of lowcarbon economy for the resource-based city with 2-tuple linguistic information," Journal of Convergence Information Technology, vol. 7, no. 17, pp. 133-139, 2012.

[11] K. T. Atanassov, "More on intuitionistic fuzzy sets," Fuzzy Sets and Systems, vol. 33, no. 1, pp. 37-45, 1989.

[12] C. Bonferroni, "Sulle medie multiple di potenze," Bolletino Matematica Italiana, vol. 5, pp. 267-270, 1950.

[13] Z. Xu and R. R. Yager, "Intuitionistic fuzzy bonferroni means," IEEE Transactions on Systems, Man, and Cybernetics B: Cybernetics, vol. 41, no. 2, pp. 568-578, 2011. 

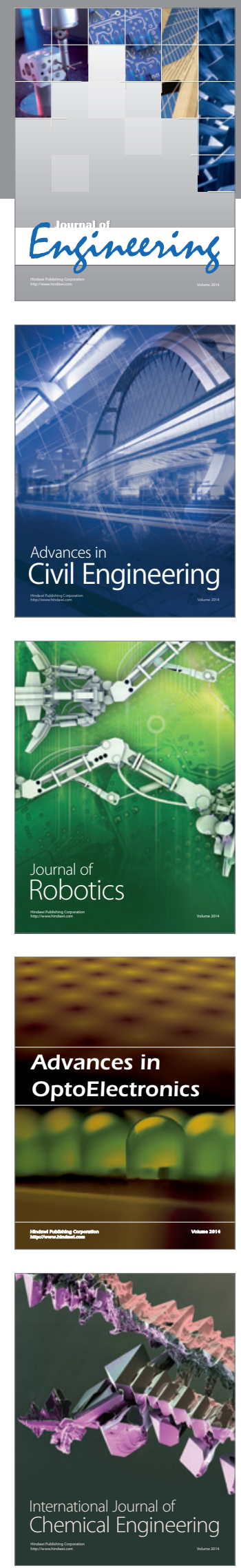

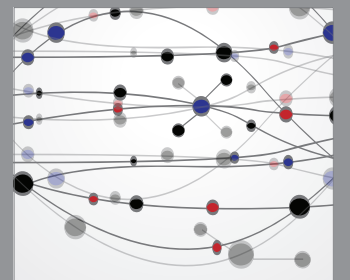

The Scientific World Journal
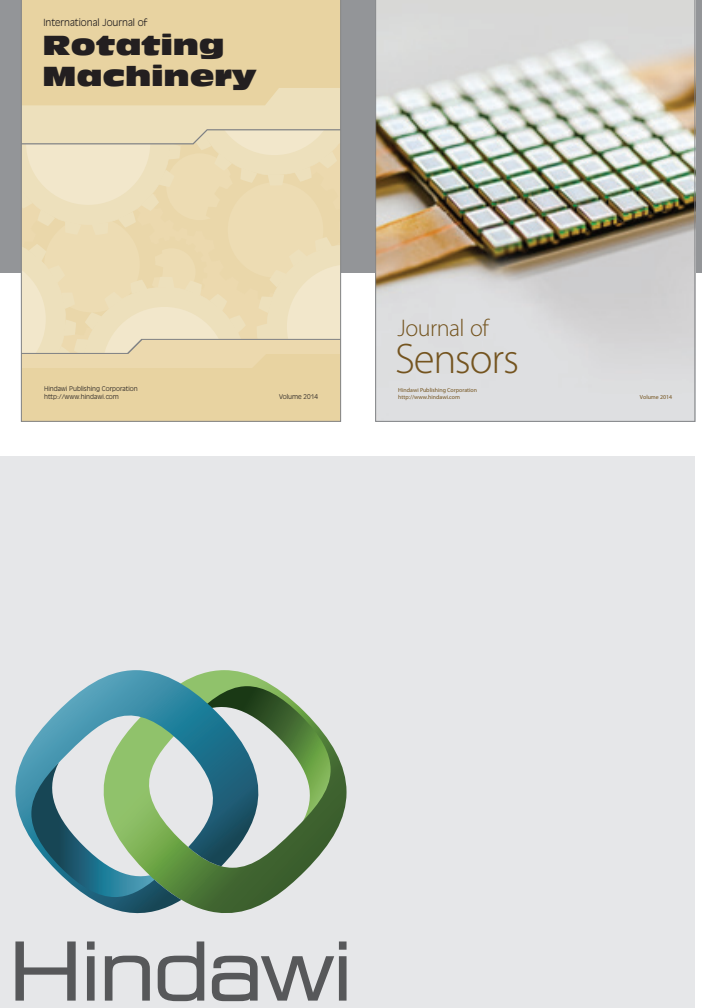

Submit your manuscripts at http://www.hindawi.com
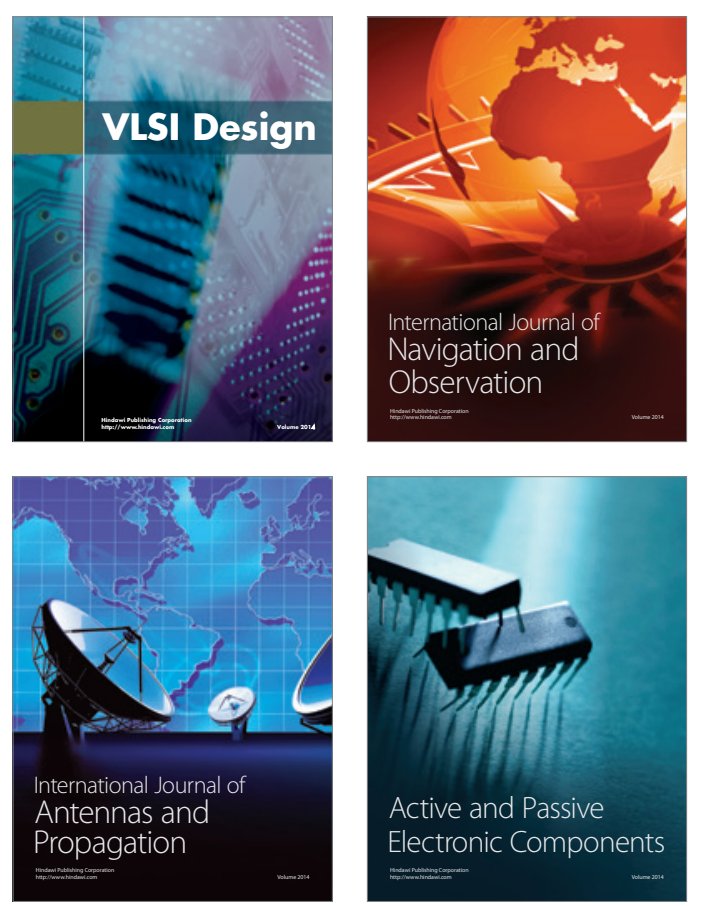
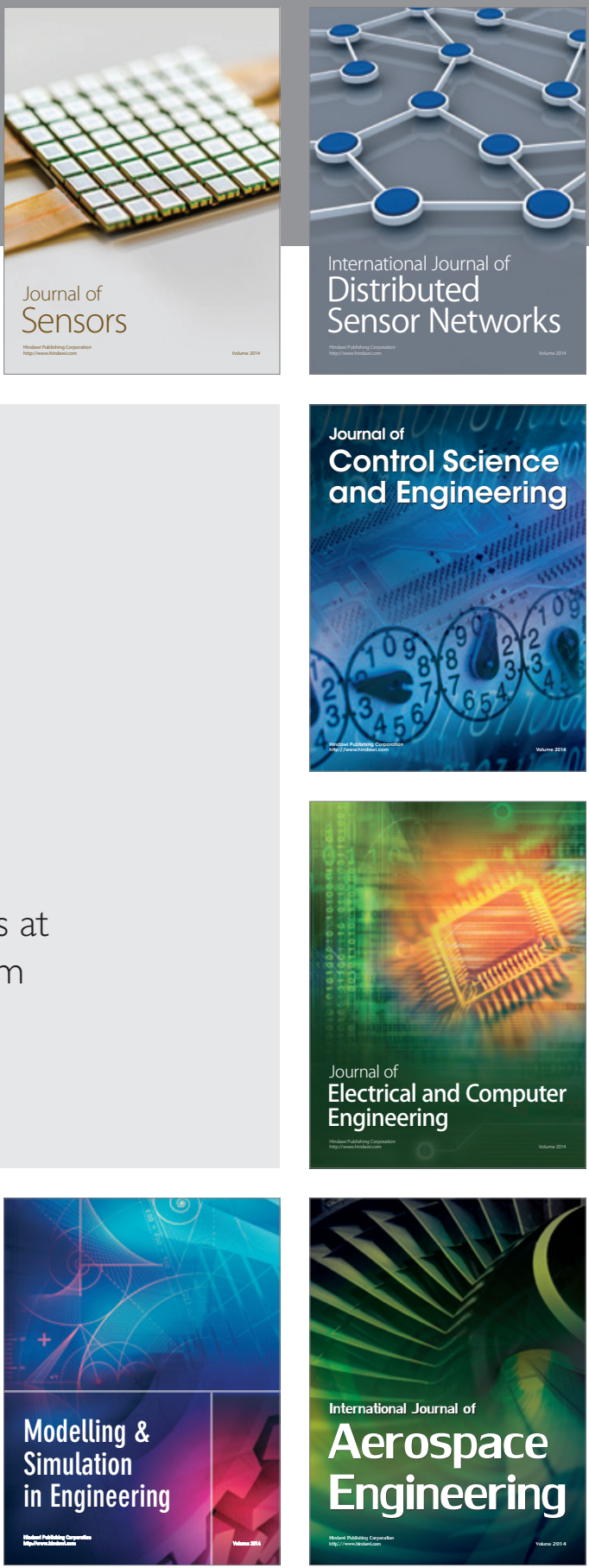

Journal of

Control Science

and Engineering
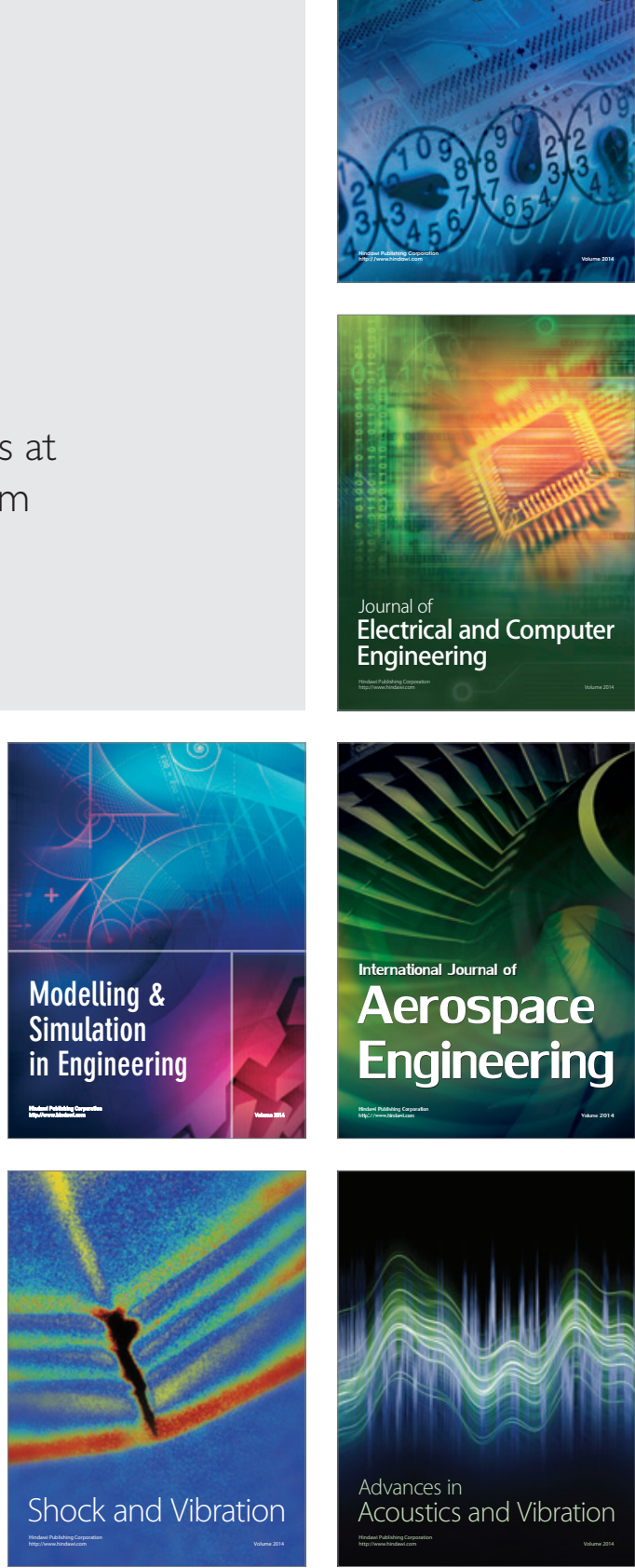